\title{
A Study on the Dynamic Interaction between Three-Axle Vehicle and Continuous Girder Bridge with Consideration of Braking Effects
}

\author{
Xuan-Toan Nguyen, ${ }^{1}$ Van-Duc Tran, ${ }^{2}$ and Nhat-Duc Hoang ${ }^{3}$ \\ ${ }^{1}$ Department of Road and Bridge Construction, Danang University of Science and Technology, 41 Le Duan, Danang 550000, Vietnam \\ ${ }^{2}$ International School, Duy Tan University, 254 Nguyen Van Linh, Danang 550000, Vietnam \\ ${ }^{3}$ Institute of Research and Development, Faculty of Civil Engineering, Duy Tan University, K7/25 Quang Trung, \\ Danang 550000, Vietnam
}

Correspondence should be addressed to Nhat-Duc Hoang; hoangnhatduc@dtu.edu.vn

Received 1 December 2016; Revised 15 February 2017; Accepted 21 February 2017; Published 15 March 2017

Academic Editor: Eric Lui

Copyright (C) 2017 Xuan-Toan Nguyen et al. This is an open access article distributed under the Creative Commons Attribution License, which permits unrestricted use, distribution, and reproduction in any medium, provided the original work is properly cited.

\begin{abstract}
Continuous girder bridges become increasingly popular because of the rapid development of highway throughout the world. Most of previous researches on vibration analysis of a multispan continuous bridge subject to complex traffic loading and vehicle dynamic interaction focus on the girder displacement not considering braking effects. In current literature, few studies have discussed the effects of braking on continuous girder bridges. In this study, we employ the finite element method (FEM) to investigate the dynamic response of continuous girder bridge due to three-axle vehicle. Vertical reaction forces of axles that change with time make bending vibration of girder increase significantly. The braking in the first span is able to create response in other spans. In addition, the dynamic impact factors are investigated by both FEM and experiments on a real bridge structure. The results of this study extend the current understanding of the bridge dynamic behaviors and can be used as additional references for bridge codes by practicing engineers.
\end{abstract}

\section{Introduction}

Dynamic interactions between vehicle and bridge were initially interested in railway engineering; they rapidly attracted attention of highway engineering. The initial researchers had studied the response of bridges subjected to vehicles moving since the 1950s of the 19th century. The first model moving loads were obtained by Willis [1]. These models consisted of a concentrated moving mass where the inertial forces of the underlying structure were ignored. Following studies have been introduced for study of the moving loads on beams with simple model $[2,3]$. As Fryba [4] introduced a fundamental study of girder due to mass roll on the train rails considering the braking effects and also studied the quasistatic distribution of braking. Kishan and Trail-Nash [5] studied the dynamic response of highway bridges due to vehicle loading considering braking force, and the resulting impact factors (IMs) may be larger than those adopted in the current design code. Gupta and Trail-Nash [6] investigated the dynamic behavior of bridge model with single span uniform girder considering the road surface irregularities and vehicle braking force. Mulcahy [7] carried out method for analysis of dynamic interaction between single span bridges and a three-axle tractor-trailer vehicle considering vehicle acceleration, braking effects, and roughness of the road surface. Yang and Wu [8] applied and developed numerical method to investigate the dynamic behavior of a bridge when vehicle was decelerating. $\mathrm{Hu}$ and Han [9] presented a nonlinear dynamic model of four-wheel-steering vehicles considering the braking force, as well as the air drag and wind effect. Law and Zhu [10] studied the dynamic behavior of continuous three spans under moving vehicle considering the roughness of the road surface. Ju and Lin [11] used the FEM to calculate the vertical vibration of girders causing 


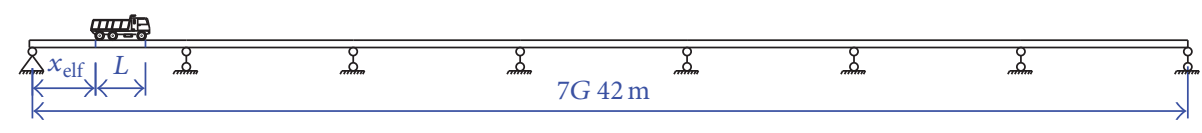

FIgURE 1: The model of a three-axle vehicle moving on a bridge.

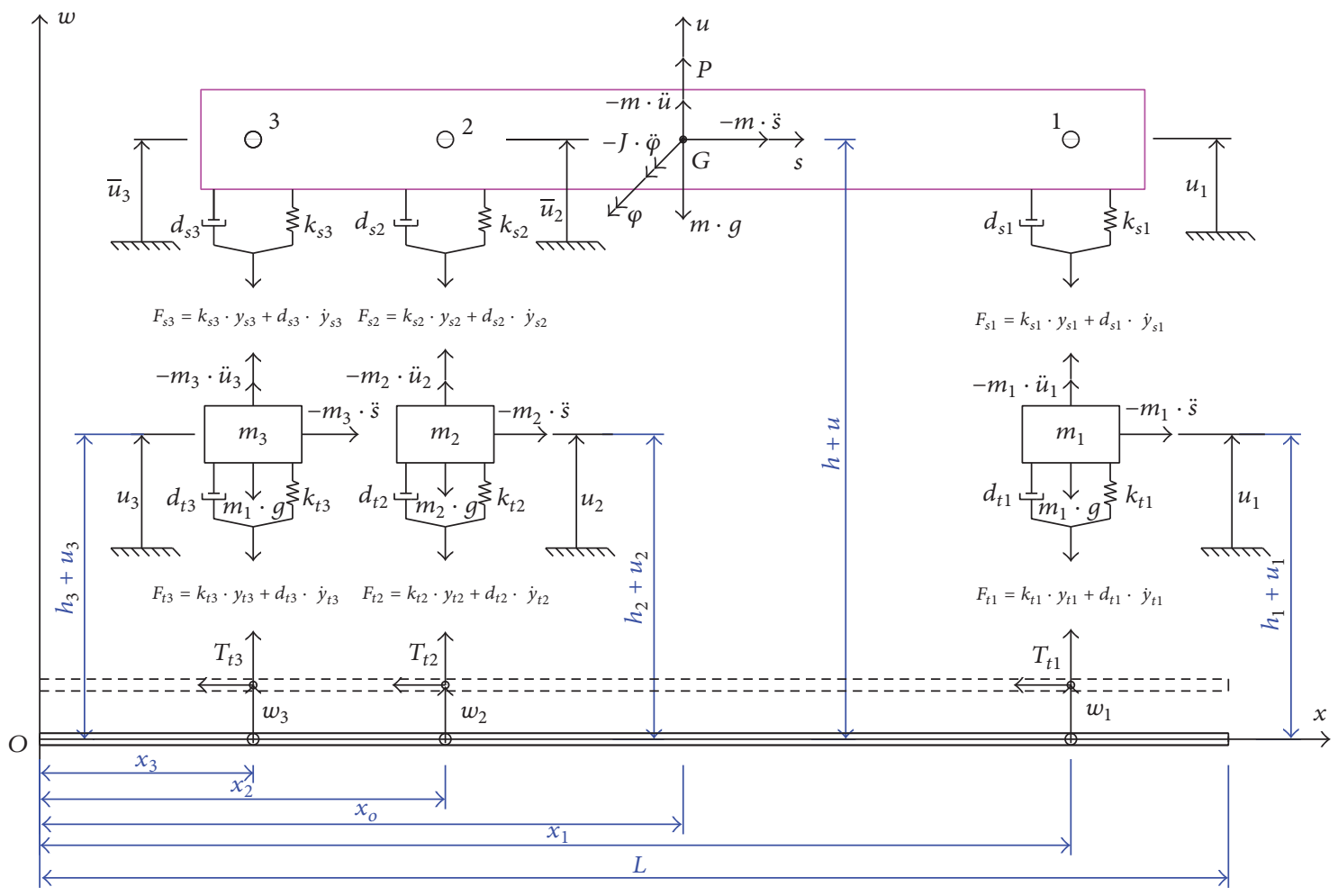

FIGURE 2: The analytical model three-axle vehicle moving on girder element.

moving vehicle due to the braking force with simple model. González et al. [12] presented an algorithm based on firstorder Tikhonov regularization and dynamic programming for the identification of moving vehicle forces on a bridge. Zhao and Uddin [13], based on routine bridge weight-inmotion results, show that a simulation approach is developed and proposed to predict bridge safety and integrity if heavy trucks experience emergency braking on the bridge. Deng et al. [14] studied the dynamic impact factors for shear and bending moment of both simply supported and continuous bridges due to vehicle loading by numerical simulations. However, of most of the previous researches on dynamic interaction between the vehicle and simply supported bridge, very few studies have focused on the multispan continuous girder bridge considering braking effects. Additionally, the field test is needed in order to obtain a clearer understanding of the relationship between dynamic interaction for bridge types and vehicle models.

This study develops the FEM to analyze the interaction between three-axle dumper truck vehicle and seven-span continuous concrete girder bridge considering the braking force. In addition, this research evaluates the effects of the girder on vertical direction when the vehicle brakes. The moving vehicle modeled by four masses, including the mass of the entire vehicle and three axles, rotational inertia of the chassis, the damping, and the suspension stiffness, spring, and tires. Numerical analysis results were compared with the experimental testing results performed on the Hoa-Xuan bridge in Danang city, Vietnam.

\section{Computational Models and Assumptions}

The diagram of a three-axle vehicle moving on the Hoa-Xuan bridge in Danang city is described as in Figure 1. The dynamic interaction model between a three-axle vehicle and a girder element considering vehicle braking effects is described as in Figure 2.

The mathematical description of Figure 2 is as follows:

$$
x_{i}=\left\{\begin{array}{ll}
v_{i} \cdot\left(t-t_{i}\right)-x_{\mathrm{elf}} ; & \text { if } t_{i} \leq t \leq t_{b i} \\
v_{i} \cdot\left(t_{b i}-t_{i}\right)+\left[\frac{a_{i} \cdot\left(t-t_{b i}\right)}{2}+v_{i}\right] \cdot\left(t-t_{b i}\right)-x_{\mathrm{elf}} ; & \text { if } t_{b i}<t \leq t_{e i},
\end{array} \quad 0 \leq x_{i} \leq L ;\right.
$$


$x_{i}=$ the coordinate of the $i$ th axes of the vehicle at time $t(i=1,2,3)$;

$t=$ time variation;

$a_{i}=$ the acceleration of the $i$ th axle when a brake is used $\left(a_{i}<0\right)$;

$L=$ the length of the girder elements;

$x_{o}=$ the coordinate of the centre of mass $m$ at time $t$;

$x_{\text {elf }}=$ the distance between the left side of the bridge and the left side of the girder element;

$v_{i}=$ the velocity of the $i$ th axle before a brake is used;

$t_{i}=$ the point of time when the $i$ th axle begins entering the bridge;

$t_{b i}=$ the point of time when a brake on the $i$ th axle is used;

$t_{e i}=$ the point of time when the $i$ th axle stops;

$P=$ is the stimulation force caused by the eccentric mass of the engine;

$m=$ the mass of vehicle body, excluding the mass of the axles;

$s=$ traveling distance of the vehicle on the bridge;

$u=$ vertical displacement of the chassis at centre of mass $m$;

$\dot{u}_{1}, \dot{u}_{2}, \dot{u}_{3}=$ the vertical displacement of chassis at the three axles;

$u_{1}, u_{2}, u_{3}=$ the vertical displacement of the three axles;

$y_{s 1}, y_{s 2}, y_{s 3}=$ the relative displacement between the chassis and the three axles;

$y_{t 1}, y_{t 2}, y_{t 3}=$ the relative displacement between the girder element and the three axles;

$h_{1}, h_{2}, h_{3}=$ the height from the centre of girder element to centre of mass $m_{1}, m_{2}, m_{3}$, respectively;

$T_{t 1}, T_{t 2}, T_{t 3}=$ the friction forces between tire and bridge surface at the three axles.

$m_{1}, m_{2}, m_{3}=$ the mass of the 1st, $2 \mathrm{nd}, 3 \mathrm{rd}$ axle, respectively;

$w_{1}, w_{2}, w_{3}=$ the displacement of girder element at 1st, 2nd, and 3rd axle, respectively;

$k_{s 1}, k_{s 2}, k_{s 3}, d_{s 1}, d_{s 2}, d_{s 3}=$ the stiffness and the damping of the three axles;

$k_{t 1}, k_{t 2}, k_{t 3}, d_{t 1}, d_{t 2}, d_{t 3}=$ the stiffness and the damping of the three tires;

$\varphi=$ the rotation angle of the chassis.

Inertial forces, damping forces, elastic forces, stimulating forces, and braking forces affecting the system are described in Figure 2. Moreover, the following assumptions are adopted:

(i) The mass of the entire vehicle and goods, excluding the mass of the axles, is transferred to the centre of masses of the system. It is equivalent to the mass $m$ and the rotational inertia $J$. (ii) The mass of the 1st axle is $m_{1}$, which is regarded as a mass point at the centre of the corresponding axle. This is the same case for the masses of 2nd and 3rd axle which are $m_{2}$ and $m_{3}$.

(iii) The chassis is hypothesised to be absolutely hard and undistorted when moving.

(iv) The materials of a girder are in the linear elastic stage. The bridge surface is flat and has the homogeneous friction coefficient over the entire bridge surface.

(v) Braking forces of the axles of vehicle are assumed to occur simultaneously. The direction of the forces between bridge surface and tires is assumed to be in the opposite direction of the movement of a vehicle as shown in Figure 2.

According to this assumption, the friction forces between bridge surface and tires are $T_{t 1}, T_{t 2}$, and $T_{t 3}$, make the vehicle decelerate gradually, and cause inertia forces: $-m_{1} \cdot \ddot{s},-m_{2} \cdot \ddot{s}$, and $-m_{3} \cdot \ddot{s}$.

The most dangerous case is when a brake is suddenly applied. In this case, the forces $T_{t 1}, T_{t 2}$, and $T_{t 3}$ are assumed to be directly proportional to loaded weight of vehicle:

$$
T_{t 1}+T_{t 2}+T_{t 3}=\left(m+m_{1}+m_{2}+m_{3}\right) \cdot g \cdot \tau,
$$

where $\tau$ is the coefficient of friction between bridge surface and tires; $g$ is the acceleration of gravity.

\section{Bending Vibration of Girder Elements due to Braking Applied to a Three-Axle Vehicle}

Base on the calculation model and assumptions in section above, the system of masses $m, m_{1}, m_{2}$, and $m_{3}$, inertia forces, damping forces, elastic forces, stimulating force, and braking forces are taken into account. In this case, braking forces are converted to friction forces $T_{t 1}, T_{t 2}$, and $T_{t 3}$ as shown in Figure 2.

Using d'Alembert's principle and considering the equilibrium of each of masses $m, m_{1}, m_{2}$, and $m_{3}$ on the vertical axis and that of system on the longitudinal axis can be obtained:

$$
\begin{array}{r}
P-m \ddot{u}-\sum_{i=1}^{n} F_{s i}-m g=0 \\
F_{s i}-F_{t i}-m_{i} \cdot \ddot{u}_{i}-m_{i} g=0 \\
\sum_{i=1}^{n} T_{t i}+\left(m+\sum_{i=1}^{n} m_{i}\right) \cdot \ddot{s}=0
\end{array}
$$

with $i$ is number of axles $(i=1,2,3)$.

Considering the equilibrium equation of the system with the $O$ point in Figure 2 can be obtained:

$$
\begin{aligned}
& (P-m \cdot \ddot{u}-m \cdot g) \cdot x_{o}+m \cdot \ddot{s} \cdot(h+u)-J \cdot \ddot{\varphi} \\
& \quad-\sum_{i=1}^{n}\left(m_{i} \cdot \ddot{u}_{i}+m_{i} \cdot g\right) \cdot x_{i}+\sum_{i=1}^{n} m_{i} \cdot \ddot{s} \cdot\left(h_{i}+u_{i}\right) \\
& \quad+\sum_{i=1}^{n}\left(T_{t i} \cdot w_{i}-F_{t i} \cdot x_{i}\right)=0,
\end{aligned}
$$


where

$$
\begin{aligned}
& F_{s i}=k_{s i} y_{s i}+d_{s i} \dot{y}_{s i} ; \\
& F_{t i}=k_{t i} y_{t i}+d_{t i} \dot{y}_{t i} ; \\
& \bar{u}_{i}=u+\left(x_{i}-x_{o}\right) \operatorname{tg} \varphi \approx u+\left(x_{i}-x_{o}\right) \varphi ; \\
& y_{s i}=\bar{u}_{i}-u_{i} \approx u+\left(x_{i}-x_{o}\right) \varphi-u_{i} ; \\
& y_{t i}=u_{i}-w_{i} .
\end{aligned}
$$

Substituting (5) into (3) and (4), the combined (2), (3), and (4) can be obtained as a set of equations:

$$
\begin{aligned}
J & \ddot{\varphi}+\sum_{i=1}^{n} d_{s i}\left(x_{i}-x_{o}\right)^{2} \cdot \dot{\varphi}+\sum_{i=1}^{n} d_{s i}\left(x_{i}-x_{o}\right) \cdot \dot{u} \\
& -\sum_{i=1}^{n} d_{s i}\left(x_{i}-x_{o}\right) \cdot \dot{u}_{i}+\sum_{i=1}^{n} k_{s i}\left(x_{i}-x_{o}\right)^{2} \cdot \varphi \\
& +\left[\sum_{i=1}^{n} k_{s i}\left(x_{i}-x_{o}\right)-m \cdot \ddot{s}\right] \cdot u \\
& -\sum_{i=1}^{n}\left[k_{s i}\left(x_{i}-x_{o}\right)+m_{i} \cdot \ddot{s}\right] \cdot u_{i}-\sum_{i=1}^{n} T_{t i} \cdot w_{i}
\end{aligned}
$$

$$
-\left(m \cdot h+\sum_{i=1}^{n} m_{i} \cdot h_{i}\right) \cdot \ddot{s}=0,
$$$$
m \cdot \ddot{u}+\sum_{i=1}^{n} d_{s i}\left(x_{i}-x_{o}\right) \cdot \dot{\varphi}+\sum_{i=1}^{n} d_{s i} \cdot \dot{u}-\sum_{i=1}^{n} d_{s i} \cdot \dot{u}_{i}
$$$$
+\sum_{i=1}^{n} k_{s i}\left(x_{i}-x_{o}\right) \cdot \varphi+\sum_{i=1}^{n} k_{s i} \cdot u-\sum_{i=1}^{n} k_{s i} \cdot u_{i}-P
$$$$
+m \cdot g=0,
$$$$
m_{i} \cdot \ddot{u}_{i}-d_{s i}\left(x_{i}-x_{o}\right) \cdot \dot{\varphi}-d_{s i} \cdot \dot{u}+\left(d_{s i}+d_{t i}\right) \cdot \dot{u}_{i}
$$$$
-k_{s i}\left(x_{i}-x_{o}\right) \cdot \varphi-k_{s i} \cdot u+\left(k_{s i}+k_{t i}\right) \cdot u_{i}-d_{t i} \cdot \dot{w}_{i}
$$$$
-k_{t i} \cdot w_{i}+m_{i} \cdot g=0 \text {, }
$$$$
\ddot{s}=-g \cdot \tau \text {. }
$$

According to Ray (2003), the differential equation of motion for the flexure vibration of damped girder due to uniform loading $p(x, z, t)$ can be written as follows:

$$
\begin{aligned}
E J_{d} & \cdot\left(\frac{\partial^{4} w}{\partial x^{4}}+\theta \cdot \frac{\partial^{5} w}{\partial x^{4} \cdot \partial t}\right)+\rho F_{d} \cdot \frac{\partial^{2} w}{\partial t^{2}}+\beta \cdot \frac{\partial w}{\partial t} \\
& =\sum_{i=1}^{n} p_{i}(x, z, t),
\end{aligned}
$$

where

$$
\begin{aligned}
& p_{i}(x, z, t)=\xi\left(x_{i}\right) \cdot F_{t i} \cdot \delta\left(x-x_{i}\right)=\xi\left(x_{i}\right) \\
& \qquad \cdot\left[-m_{i} \cdot \ddot{u}_{i}+d_{s i}\left(x_{i}-x_{o}\right) \cdot \dot{\varphi}+d_{s i} \cdot \dot{u}-d_{s i} \cdot \dot{u}_{i}+k_{s i}\left(x_{i}-x_{o}\right) \cdot \varphi+k_{s i} \cdot u-k_{s i} \cdot u_{i}-m_{i} \cdot g\right] \cdot \delta\left(x-x_{i}\right) \\
& \text { with } \xi\left(x_{i}\right)=\left\{\begin{array}{ll}
1, & \text { if } 0 \leq x_{i} \leq L \\
0, & \text { if } x_{i}<0, x_{i}>L
\end{array}\right. \text { is the logic control signal function; }
\end{aligned}
$$

$\delta \cdot\left(x-x_{i}\right)$ is the Dirac delta function;

$x_{i}$ is determined by (1);

$w$ is deflection of the girder element;

$F_{d}$ is the cross-sectional area of the girder;

$J_{d}$ is the second moment of area the girder;

$E$ is Young's modulus;

$E J_{d}$ is the flexural rigidity of girder element;

$\rho F_{d}$ is the mass of girder per unit length;

$\theta$ and $\beta$ are the coefficient of internal friction and external friction.

The Galerkin method and Green theory are applied to (6), (7), and (8) which transform into matrix form, and the differential equations of girder element can be written in a matrix form as follows:

$$
\left[M_{e}\right] \cdot\{\ddot{q}\}+\left[C_{e}\right] \cdot\{\dot{q}\}+\left[K_{e}\right] \cdot\{q\}=\left\{f_{e}\right\},
$$

where $\{\ddot{q}\},\{\dot{q}\},\{q\}$, and $\left\{f_{e}\right\}$ are the complex acceleration vector, complex velocity vector, complex displacement vector, and complex forces vector, respectively.

$$
\begin{aligned}
& \{\ddot{q}\}=\left\{\begin{array}{c}
\ddot{w}_{e} \\
\ddot{z}
\end{array}\right\} ; \\
& \{\dot{q}\}=\left\{\begin{array}{c}
\dot{w}_{e} \\
\dot{z}
\end{array}\right\} ;
\end{aligned}
$$




$$
\begin{gathered}
\{q\}=\left\{\begin{array}{c}
w_{e} \\
z
\end{array}\right\} ; \\
\left\{f_{e}\right\}=\left\{\begin{array}{c}
f_{w} \\
f_{z}
\end{array}\right\} ; \\
\left\{w_{e}\right\}=\left\{\begin{array}{c}
u_{x 1} \\
w_{y 1} \\
\varphi_{1} \\
u_{x 2} \\
w_{y 2} \\
\varphi_{2}
\end{array}\right\} ; \\
\{z\}=\left\{\begin{array}{c}
\varphi \\
u_{1} \\
\vdots \\
u_{n}
\end{array}\right\},
\end{gathered}
$$

where $u_{x 1}, w_{y 1}$, and $\varphi_{1}$ are the axial displacement, flexural deflection, and rotation angle of the left end of element, respectively; $u_{x 2}, w_{y 2}$, and $\varphi_{2}$ are the axial displacement, flexural deflection, and rotation angle of the right end of element, respectively; $\left[M_{e}\right],\left[C_{e}\right]$, and $\left[K_{e}\right]$ are the mass matrix, damping matrix, and stiffness matrix, respectively.

$$
\begin{aligned}
& {\left[M_{e}\right]=\left[\begin{array}{ll}
M_{w w} & M_{w z} \\
M_{z w} & M_{z z}
\end{array}\right] ;} \\
& {\left[C_{e}\right]=\left[\begin{array}{ll}
C_{w w} & C_{w z} \\
C_{z w} & C_{z z}
\end{array}\right] ;} \\
& {\left[K_{e}\right]=\left[\begin{array}{ll}
K_{w w} & K_{w z} \\
K_{z w} & K_{z z}
\end{array}\right],}
\end{aligned}
$$

where $\left[M_{w w}\right],\left[C_{w w}\right]$, and $\left[K_{w w}\right]$ are mass, damping, and stiffness matrices of the girder elements, respectively. They can be found in Zienkiewicz (2000).

$$
\begin{aligned}
& {\left[M_{w z}\right]=\left[\begin{array}{ccccccc}
0 & 0 & m_{1} P_{11} & \cdots & m_{i} P_{1 i} & \cdots & m_{n} P_{1 n} \\
0 & 0 & m_{1} P_{21} & \cdots & m_{i} P_{2 i} & \cdots & m_{n} P_{2 n} \\
0 & 0 & m_{1} P_{31} & \cdots & m_{i} P_{3 i} & \cdots & m_{n} P_{3 n} \\
0 & 0 & m_{1} P_{41} & \cdots & m_{i} P_{4 i} & \cdots & m_{n} P_{4 n}
\end{array}\right]} \\
& \left\{f_{w}\right\}=-\left\{\begin{array}{l}
g\left(m_{1} P_{11}+\cdots+m_{i} P_{1 i}+\cdots+m_{n} P_{1 n}\right) \\
g\left(m_{1} P_{21}+\cdots+m_{i} P_{2 i}+\cdots+m_{n} P_{2 n}\right) \\
g\left(m_{1} P_{31}+\cdots+m_{i} P_{3 i}+\cdots+m_{n} P_{3 n}\right) \\
g\left(m_{1} P_{41}+\cdots+m_{i} P_{4 i}+\cdots+m_{n} P_{4 n}\right)
\end{array}\right\}, \\
& {\left[C_{w z}\right]=-\left[\begin{array}{lllllll}
\sum_{i=1}^{n} d_{s i}\left(x_{i}-x_{o}\right) P_{1 i} & \sum_{i=1}^{n} d_{s i} P_{1 i} & -d_{s 1} P_{11} & \cdots & -d_{s i} P_{1 i} & \cdots & -d_{s n} P_{1 n} \\
\sum_{i=1}^{n} d_{s i}\left(x_{i}-x_{o}\right) P_{2 i} & \sum_{i=1}^{n} d_{s i} P_{2 i} & -d_{s 1} P_{21} & \cdots & -d_{s i} P_{2 i} & \cdots & -d_{s n} P_{2 n} \\
\sum_{i=1}^{n} d_{s i}\left(x_{i}-x_{o}\right) P_{3 i} & \sum_{i=1}^{n} d_{s i} P_{3 i} & -d_{s 1} P_{31} & \cdots & -d_{s i} P_{3 i} & \cdots & -d_{s n} P_{3 n} \\
\sum_{i=1}^{n} d_{s i}\left(x_{i}-x_{o}\right) P_{4 i} & \sum_{i=1}^{n} d_{s i} P_{4 i} & -d_{s 1} P_{41} & \cdots & -d_{s i} P_{4 i} & \cdots & -d_{s n} P_{4 n}
\end{array}\right],} \\
& {\left[K_{w z}\right]=-\left[\begin{array}{lllllll}
\sum_{i=1}^{n} k_{s i}\left(x_{i}-x_{o}\right) P_{1 i} & \sum_{i=1}^{n} k_{s i} P_{1 i} & -k_{s 1} P_{11} & \cdots & -k_{s i} P_{1 i} & \cdots & -k_{s n} P_{1 n} \\
\sum_{i=1}^{n} k_{s i}\left(x_{i}-x_{o}\right) P_{2 i} & \sum_{i=1}^{n} k_{s i} P_{2 i} & -k_{s 1} P_{21} & \cdots & -k_{s i} P_{2 i} & \cdots & -k_{s n} P_{2 n} \\
\sum_{i=1}^{n} k_{s i}\left(x_{i}-x_{o}\right) P_{3 i} & \sum_{i=1}^{n} k_{s i} P_{3 i} & -k_{s 1} P_{31} & \cdots & -k_{s i} P_{3 i} & \cdots & -k_{s n} P_{3 n} \\
\sum_{i=1}^{n} k_{s i}\left(x_{i}-x_{o}\right) P_{4 i} & \sum_{i=1}^{n} k_{s i} P_{4 i} & -k_{s 1} P_{41} & \cdots & -k_{s i} P_{4 i} & \cdots & -k_{s n} P_{4 n}
\end{array}\right],}
\end{aligned}
$$




$$
\begin{aligned}
& {\left[M_{z z}\right]=\left[\begin{array}{ccccccc}
J & 0 & 0 & \cdots & 0 & \cdots & 0 \\
0 & m & 0 & \cdots & 0 & \cdots & 0 \\
0 & 0 & m_{1} & \cdots & 0 & \cdots & 0 \\
\cdots & \cdots & \cdots & \cdots & \cdots & \cdots & \cdots \\
0 & 0 & 0 & \cdots & m_{i} & \cdots & 0 \\
\cdots & \cdots & \cdots & \cdots & \cdots & \cdots & \cdots \\
0 & 0 & 0 & \cdots & 0 & \cdots & m_{n}
\end{array}\right]} \\
& \left\{f_{z}\right\}=-\left\{\begin{array}{c}
\left(m h+\sum_{i=1}^{n} m_{i} h_{i}\right) \cdot \ddot{s} \\
P-m g \\
-m_{1} g \\
\ldots \\
-m_{i} g \\
\ldots \\
-m_{n} g
\end{array}\right\} \text {, } \\
& {\left[C_{z z}\right]=\left[\begin{array}{ccccccc}
\sum_{i=1}^{n} d_{s i}\left(x_{i}-x_{o}\right)^{2} & \sum_{i=1}^{n} d_{s i}\left(x_{i}-x_{o}\right) & -d_{s 1}\left(x_{1}-x_{o}\right) & \cdots & -d_{s i}\left(x_{i}-x_{o}\right) & \cdots & -d_{s n}\left(x_{n}-x_{o}\right) \\
\sum_{i=1}^{n} d_{s i}\left(x_{i}-x_{o}\right) & \sum_{i=1}^{n} d_{s i} & -d_{s 1} & \ldots & -d_{s i} & \ldots & -d_{s n} \\
-d_{s 1}\left(x_{1}-x_{o}\right) & -d_{s 1} & d_{s 1}+d_{t 1} & \ldots & 0 & \ldots & 0 \\
\ldots & \ldots & \ldots & \ldots & \ldots & \ldots & \ldots \\
-d_{s i}\left(x_{i}-x_{o}\right) & -d_{s i} & 0 & \ldots & d_{s i}+d_{t i} & \ldots & 0 \\
\ldots & \ldots & \ldots & \ldots & \ldots & \ldots & \ldots \\
-d_{s n}\left(x_{n}-x_{o}\right) & -d_{s n} & 0 & \ldots & 0 & \ldots & d_{s n}+d_{t n}
\end{array}\right],} \\
& {\left[K_{z z}\right]=\left[\begin{array}{ccccccc}
\sum_{i=1}^{n} k_{s i}\left(x_{i}-x_{o}\right)^{2} & \sum_{i=1}^{n} k_{s i}\left(x_{i}-x_{o}\right) & -k_{s 1}\left(x_{1}-x_{o}\right) & \cdots & -k_{s i}\left(x_{i}-x_{o}\right) & \cdots & -k_{s n}\left(x_{n}-x_{o}\right) \\
\sum_{i=1}^{n} k_{s i}\left(x_{i}-x_{o}\right) & \sum_{i=1}^{n} k_{s i} & -k_{s 1} & \cdots & -k_{s i} & \ldots & -k_{s n} \\
-k_{s 1}\left(x_{1}-x_{o}\right) & -k_{s 1} & k_{s 1}+k_{t 1} & \ldots & 0 & \ldots & 0 \\
\ldots & \ldots & \ldots & \ldots & \ldots & \ldots & \ldots \\
-k_{s i}\left(x_{i}-x_{o}\right) & -k_{s i} & 0 & \ldots & k_{s i}+k_{t i} & \ldots & 0 \\
\ldots & \ldots & \ldots & \ldots & \cdots & \ldots & \ldots \\
-k_{s n}\left(x_{n}-x_{o}\right) & -k_{s n} & 0 & \ldots & 0 & \ldots & k_{s n}+k_{t n}
\end{array}\right] \text {, }}
\end{aligned}
$$

$\left[M_{z w}\right]=0$;

$$
\left[C_{z w}\right]=\left[\begin{array}{cccc}
0 & 0 & 0 & 0 \\
0 & 0 & 0 & 0 \\
-d_{t 1} P_{11} & -d_{t 1} P_{21} & -d_{t 1} P_{31} & -d_{t 1} P_{41} \\
\cdots & \cdots & \cdots & \cdots \\
-d_{t i} P_{1 i} & -d_{t i} P_{2 i} & -d_{t i} P_{3 i} & -d_{t i} P_{4 i} \\
\cdots & \cdots & \cdots & \cdots \\
-d_{t n} P_{1 n} & -d_{t n} P_{2 n} & -d_{t n} P_{3 n} & -d_{t n} P_{4 n}
\end{array}\right],
$$




$$
\left[K_{z w}\right]=-\left[\begin{array}{cccc}
\sum_{i=1}^{n} T_{t i} \cdot P_{1 i} & \sum_{i=1}^{n} T_{t i} \cdot P_{2 i} & \sum_{i=1}^{n} T_{t i} \cdot P_{3 i} & \sum_{i=1}^{n} T_{t i} \cdot P_{4 i} \\
0 & 0 & 0 & 0 \\
d_{t 1} \cdot \dot{P}_{11}+k_{t 1} \cdot P_{11} & d_{t 1} \cdot \dot{P}_{21}+k_{t 1} \cdot P_{21} & d_{t 1} \cdot \dot{P}_{31}+k_{t 1} \cdot P_{31} & d_{t 1} \cdot \dot{P}_{41}+k_{t 1} \cdot P_{41} \\
\ldots & \ldots & \ldots & \ldots \\
d_{t i} \cdot \dot{P}_{1 i}+k_{t i} \cdot P_{1 i} & d_{t i} \cdot \dot{P}_{2 i}+k_{t i} \cdot P_{2 i} & d_{t i} \cdot \dot{P}_{3 i}+k_{t i} \cdot P_{3 i} & d_{t i} \cdot \dot{P}_{4 i}+k_{t i} \cdot P_{4 i} \\
\ldots & \ldots & \ldots & \ldots \\
d_{t n} \cdot \dot{P}_{1 n}+k_{t n} \cdot P_{1 n} & d_{t n} \cdot \dot{P}_{2 n}+k_{t n} \cdot P_{2 n} & d_{t n} \cdot \dot{P}_{3 n}+k_{t n} \cdot P_{3 n} & d_{t n} \cdot P_{4 n}+k_{t n} \cdot P_{4 n}
\end{array}\right]
$$

in which

$$
\begin{aligned}
& P_{1 i}=\frac{\xi\left(x_{i}\right)}{L} \cdot \tau \cdot\left(L-x_{i}\right), \\
& P_{2 i}=\frac{\xi\left(x_{i}\right)}{L^{3}} \cdot\left(L^{3}-3 L \cdot x_{i}^{2}+2 x_{i}^{3}\right), \\
& P_{3 i}=\frac{\xi\left(x_{i}\right)}{L^{2}} \cdot\left(L^{2} \cdot x_{i}-2 L \cdot x_{i}^{2}+x_{i}^{3}\right), \\
& P_{4 i}=\frac{\xi\left(x_{i}\right)}{L} \cdot \tau \cdot x_{i}, \\
& P_{5 i}=\frac{\xi\left(x_{i}\right)}{L^{3}} \cdot x_{i}^{2}\left(3 L-2 x_{i}\right), \\
& P_{6 i}=\frac{\xi\left(x_{i}\right)}{L^{2}} \cdot x_{i}^{2}\left(x_{i}-L\right) ;
\end{aligned}
$$

$x_{i}$ is computed by (1).

\section{Application of the FEM in Analysis Vibration of Hoa-Xuan Bridge}

Hoa-Xuan bridge is a continuous concrete girder bridge with spans of $7 \times 42 \mathrm{~m}$, shown in Figure 1 . The cross section of the concrete girder bridge and position of truck is shown in Figure 3. The three-axle vehicle used in the numerical simulation and the field test is ASIA dumper truck as shown in Figure 4. Applying the algorithm of the FEM [15], the vibration differential equation for the system is shown as follows:

$$
[M] \cdot\{\ddot{Q}\}+[C] \cdot\{\dot{Q}\}+[K] \cdot\{Q\}=\{F\},
$$

where $[M],[C]$, and $[K]$ are mass matrix, damper matrix, and stiffness matrix of the system; $\{\ddot{Q}\},\{\dot{Q}\},\{Q\}$, and $\{F\}$ are acceleration vector, the velocity vector, the deflection vector, and the force vector of the system.

Equation (15) is computed by the Runge-Kutta-Merson method. The numerical values of the parameters were used in the computer simulation and the field test as follows.

The parameters of concrete girder are as follows: $E=$ $3230769230\left(\mathrm{~kg} / \mathrm{m}^{2}\right) ; J_{d}=0.6879\left(\mathrm{~m}^{4}\right) ; F_{d}=1.3776\left(\mathrm{~m}^{2}\right) ; \rho F_{d}$ $=3800(\mathrm{~kg} / \mathrm{m}) ; \theta=0.027 ; \beta=0.01 ; \tau=0.25 ; g=9.81\left(\mathrm{~m} / \mathrm{s}^{2}\right)$.
The three-axle vehicle parameters are as follows: $m=$ $14060(\mathrm{~kg}) ; m_{1}=60(\mathrm{~kg}) ; m_{2}=110(\mathrm{~kg}) ; m_{3}=110(\mathrm{~kg}) ; P=0 ;$ $b_{1}=3.25(\mathrm{~m}) ; b_{2}=1.10(\mathrm{~m}) ; b_{3}=2.4(\mathrm{~m}) ; h=1.26(\mathrm{~m}) ; h_{1}=h_{2}$ $=h_{3}=0.6(\mathrm{~m}) ; k_{1 s}=1200000(\mathrm{~N} / \mathrm{m}) ; k_{1 t}=1600000(\mathrm{~N} / \mathrm{m})$; $k_{2 s}=k_{3 s}=2600000(\mathrm{~N} / \mathrm{m}) ; k_{2 t}=k_{3 t}=3200000(\mathrm{~N} / \mathrm{m}) ; d_{1 s}=$ $7344(\mathrm{~N} \cdot \mathrm{s} / \mathrm{m}) ; d_{1 t}=3670(\mathrm{~N} \cdot \mathrm{s} / \mathrm{m}) ; d_{2 s}=d_{3 s}=4000(\mathrm{~N} \cdot \mathrm{s} / \mathrm{m}) ;$ $d_{2 t}=d_{3 t}=8000(\mathrm{~N} \cdot \mathrm{s} / \mathrm{m})$.

The FEM results are compared with those of corresponding experimental investigation for Hoa-Xuan bridge response with ASIA vehicle loading. The girder deflections of the HoaXuan bridge caused by ASIA vehicle moving on the first span and which used sudden braking at the velocity of $30 \mathrm{~km} / \mathrm{h}$ were investigated. The FEM results and experimental results are shown in Figures 5-8.

The results of the maximum dynamic deflections and the dynamic magnification factor of the Hoa-Xuan bridge caused by ASIA vehicle, running at $30 \mathrm{~km} / \mathrm{h}$ and with a brake being applied on the first span, are shown in Table 1 . The deflection due to Dead Load only is the blue curved line on the graph as shown in Figures 5(a)-8(a) for the FEM result.

The notations in Table 1 are described as follows:

$$
(1+\mathrm{IM})=\frac{U_{D}}{U_{S}},
$$

where IM is dynamic impact factor, also known as the dynamic load allowance in the AASHTO [16] code with the $\mathrm{IM}=0.33 ; U_{S}$ is the maximum static deflection of girder; $U_{D}$ is the maximum dynamic deflection of girder with braking force; $\Delta U_{D}$ is the difference of $U_{D}$ between from FEM result and experiment result; $\Delta(1+\mathrm{IM})$ is the difference of $(1+\mathrm{IM})$ between from FEM result and experiment result.

As can be seen from Table 1, the FEM results agree well when compared with the experimental results. The difference of dynamic deflection of girder between the FEM results and the experimental results varies from $0.6 \%$ to $6.3 \%$. Meanwhile, the difference of dynamic deflection of girder between the FEM results and the experimental results of $(1+$ IM) deflection varies from $3.1 \%$ to $5.9 \%$. Based on the FEM and experimental results, the maximum dynamic impact factor of deflection is appreciable. The errors between the FEM and experimental results are significant, and they can be caused by the following reasons: 

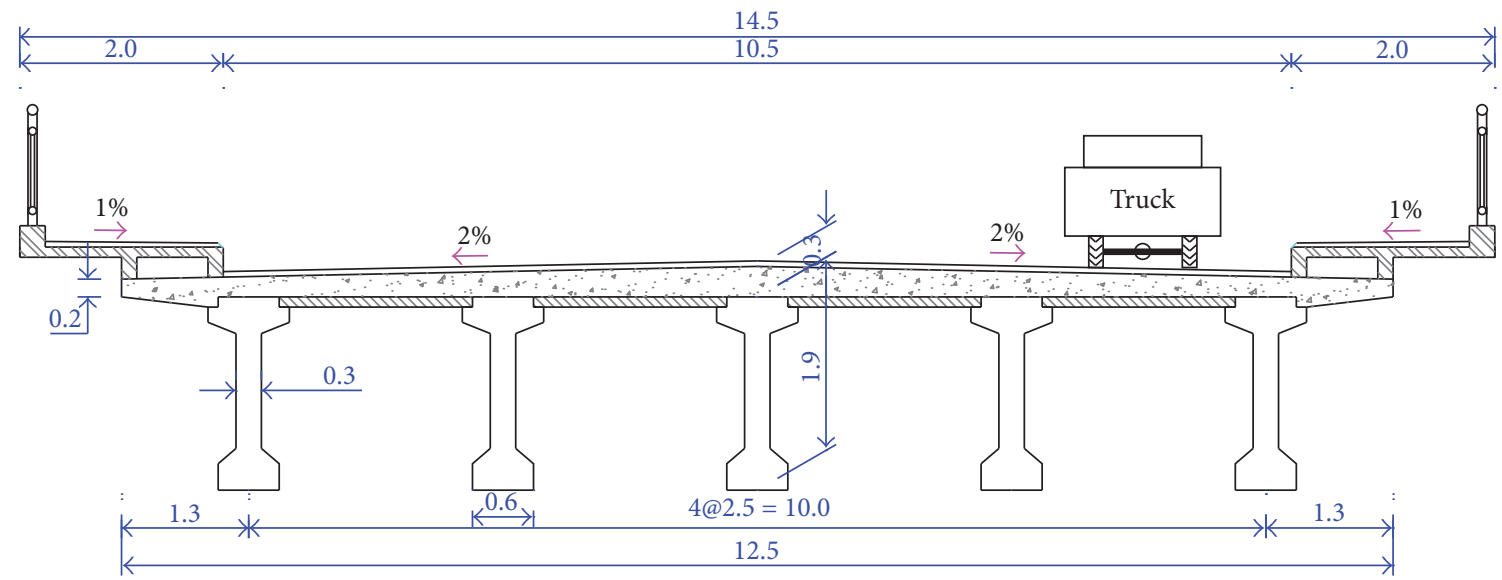

Unit: $\mathrm{m}$

FIGURE 3: Cross section of the concrete girder bridge with loading position of the truck.

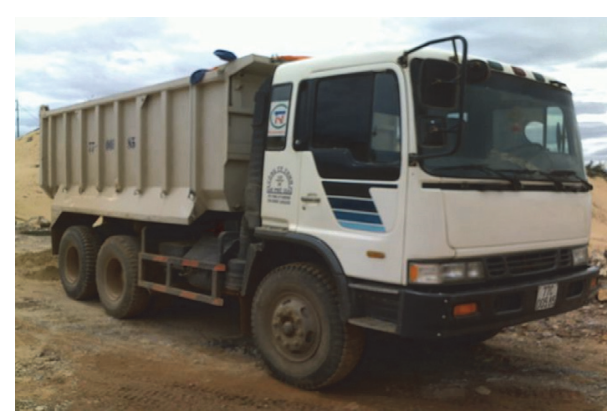

(a)

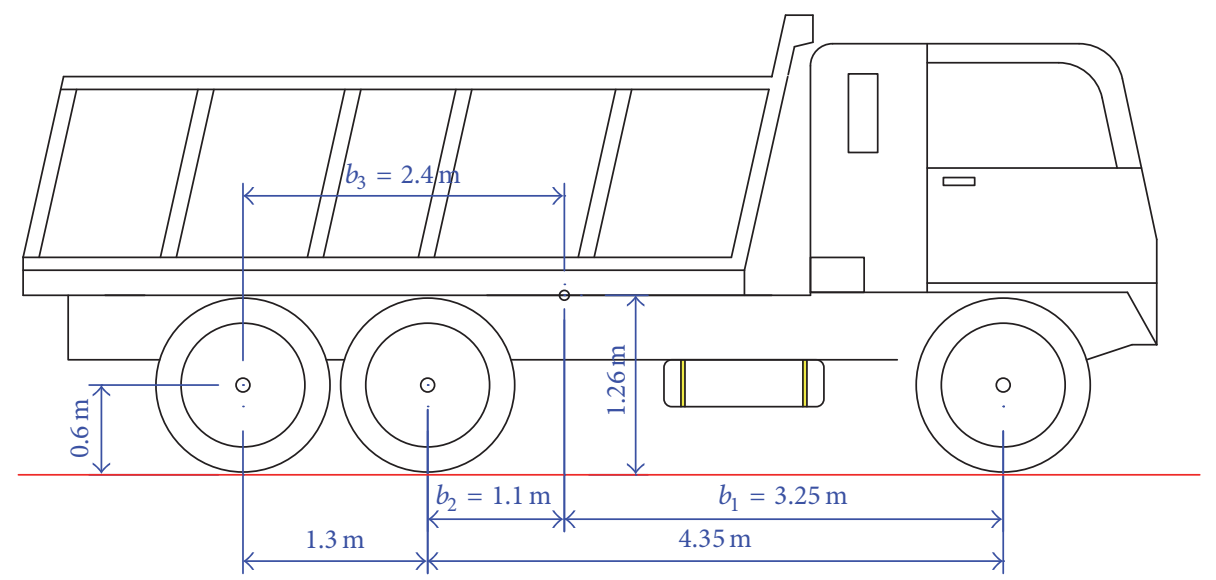

(b)

FIgURE 4: The ASIA dumper truck: (a) picture of vehicle; (b) vehicle dimensional parameters.

(1) When the vehicle braked, the braking forces did not happen simultaneously at all wheels.

(2) The chassis stiffness for the FEM is assumed absolutely rigid, while the actual stiffness of chassis is comparative.
(3) The input parameters of the three-axle vehicle and the bridge for the FEM analysis are not measured exactly as desired.

In the experimental results, the $(1+$ IM) increases with an increase in velocity at sudden braking which is shown from Figures 9-13. Therefore, the $(1+$ IM) decreases with 


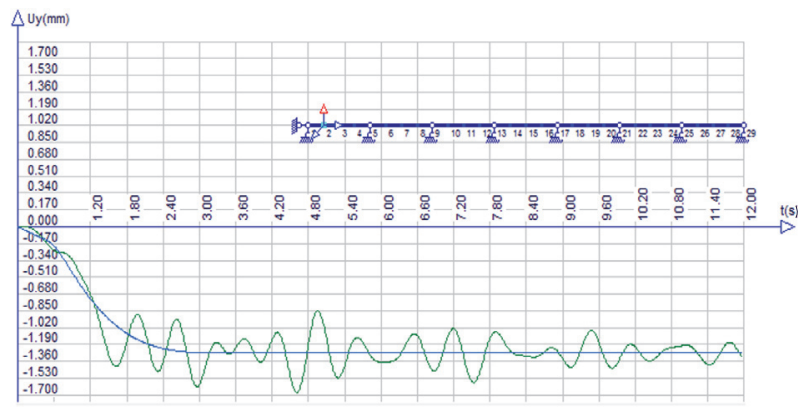

(a)

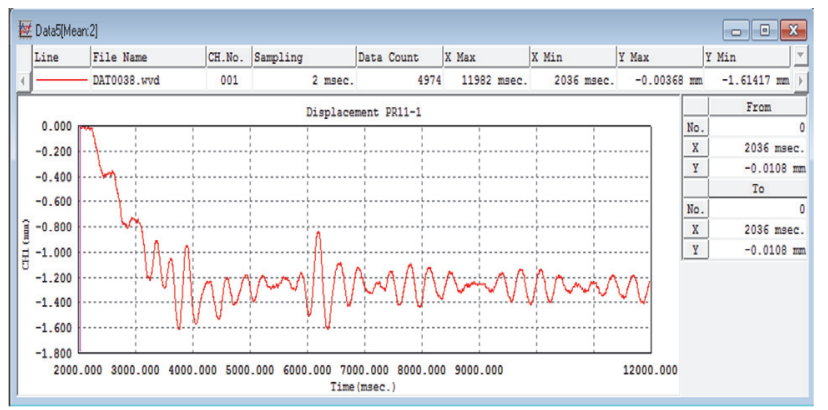

(b)

FIGURE 5: Time history of quarter-span deflection caused by the braking of the vehicle at quarter 1st span position: (a) the FEM result; (b) experimental result.

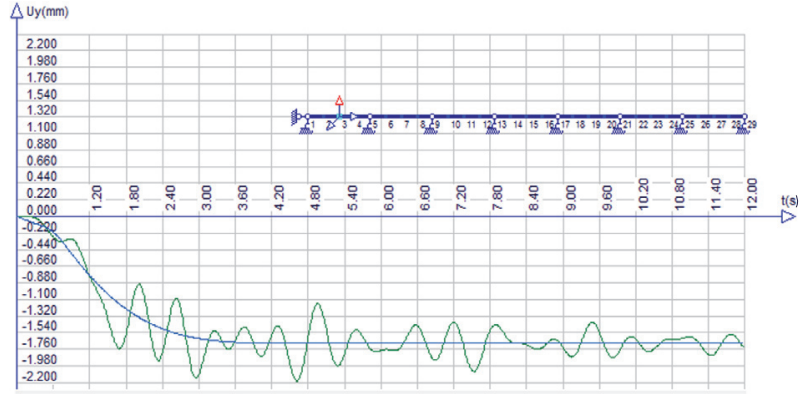

(a)

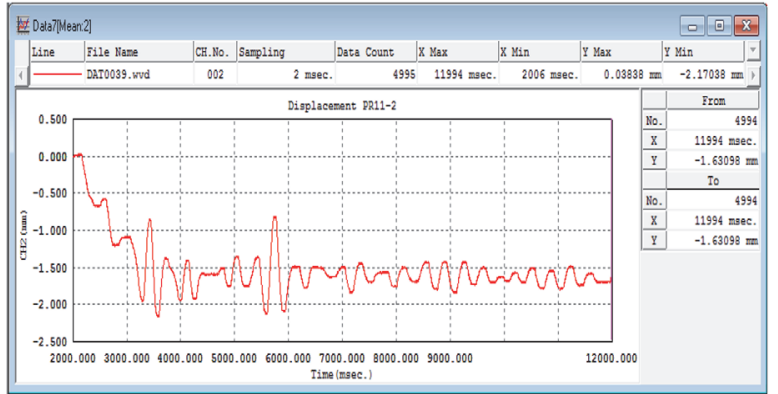

(b)

FIGURE 6: Time history of midspan deflection caused by the braking at quarter 1st span position: (a) the FEM result; (b) experimental result.

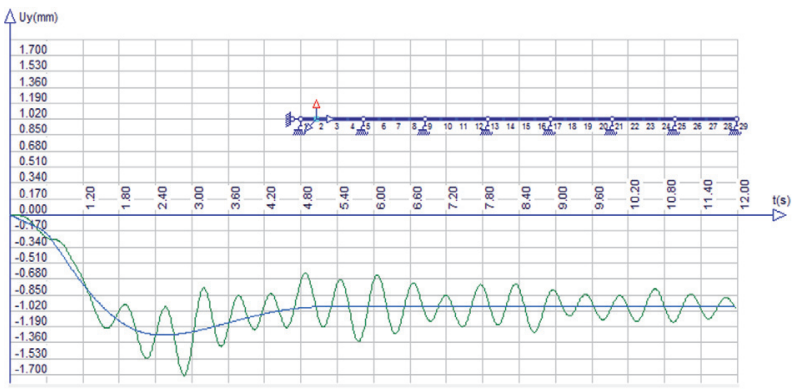

(a)

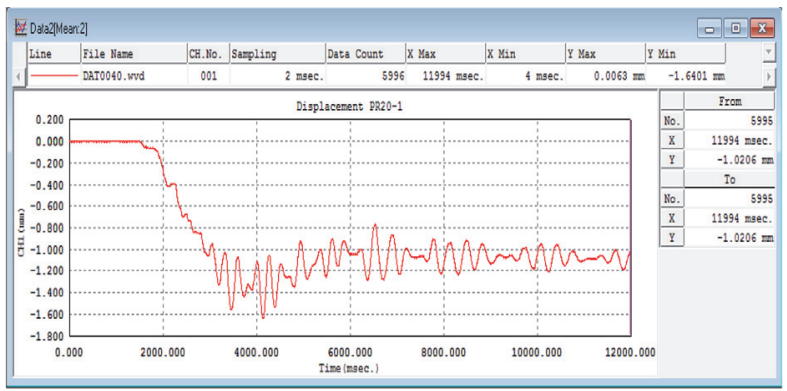

(b)

FIGURE 7: Time history of quarter-span deflection caused by the braking at mid-1st span position: (a) the FEM result; (b) experimental result.

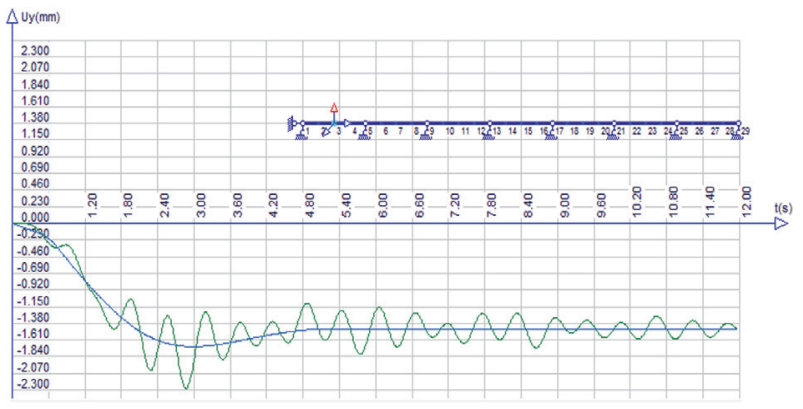

(a)

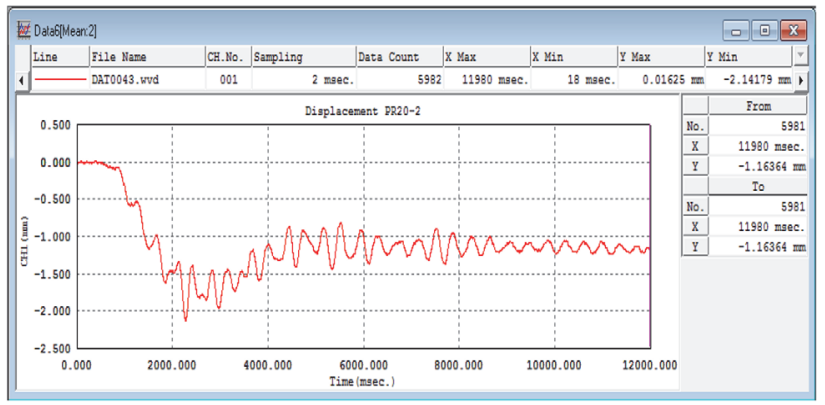

(b)

FIGURE 8: Time history of midspan deflection caused by the braking at mid-1st span position: (a) the FEM result; (b) experimental result. 
TABLE 1: The results of the deflections of the Hoa-Xuan Bridge caused by a ASIA vehicle.

\begin{tabular}{|c|c|c|c|c|c|c|c|c|c|}
\hline \multirow[t]{2}{*}{ Positions of deflections } & \multirow{2}{*}{$\begin{array}{l}\text { Braking } \\
\text { positions }\end{array}$} & \multicolumn{3}{|c|}{ The FEM results } & \multicolumn{3}{|c|}{ The experimental results } & \multicolumn{2}{|c|}{$\begin{array}{l}\text { The difference } \\
\text { between from FEM } \\
\text { and experiment }\end{array}$} \\
\hline & & $\begin{array}{c}U_{D} \\
(\mathrm{~mm})\end{array}$ & $\begin{array}{c}U_{S} \\
(\mathrm{~mm})\end{array}$ & $(1+\mathrm{IM})$ & $\begin{array}{c}U_{D} \\
(\mathrm{~mm})\end{array}$ & $\begin{array}{c}U_{S} \\
(\mathrm{~mm})\end{array}$ & $(1+\mathrm{IM})$ & $\begin{array}{c}\Delta U_{D} \\
(\%)\end{array}$ & $\begin{array}{c}\Delta(1+\mathrm{IM}) \\
(\%)\end{array}$ \\
\hline $1 / 4$ of 1 st span & $1 / 4$ of 1st span & 1.678 & 1.277 & 1.314 & 1.614 & 1.301 & 1.241 & 4.0 & 5.9 \\
\hline $1 / 2$ 1st span & $1 / 4$ of 1 st span & 2.182 & 1.682 & 1.297 & 2.170 & 1.750 & 1.240 & 0.6 & 4.3 \\
\hline $1 / 4$ of 1st span & $1 / 2$ 1st span & 1.708 & 1.277 & 1.338 & 1.640 & 1.263 & 1.298 & 4.1 & 3.1 \\
\hline 1/2 1st span & 1/2 1st span & 2.278 & 1.700 & 1.340 & 2.142 & 1.657 & 1.293 & 6.3 & 3.6 \\
\hline
\end{tabular}

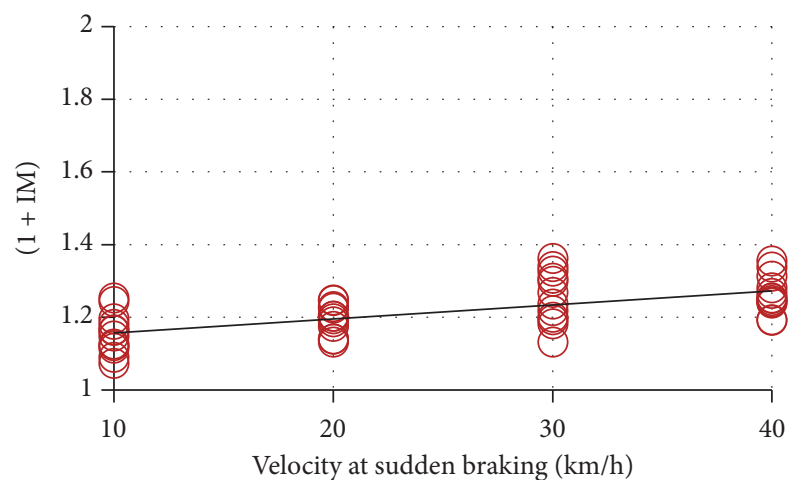

FIGURE 9: $(1+\mathrm{IM})$ versus velocity at sudden braking of $L / 8$ position.

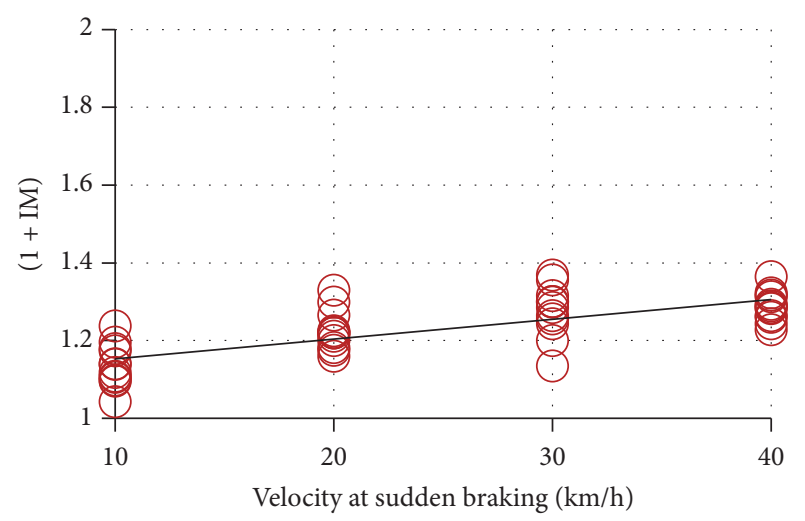

FIGURE 10: $(1+\mathrm{IM})$ versus velocity at sudden braking of $L / 4$ position.

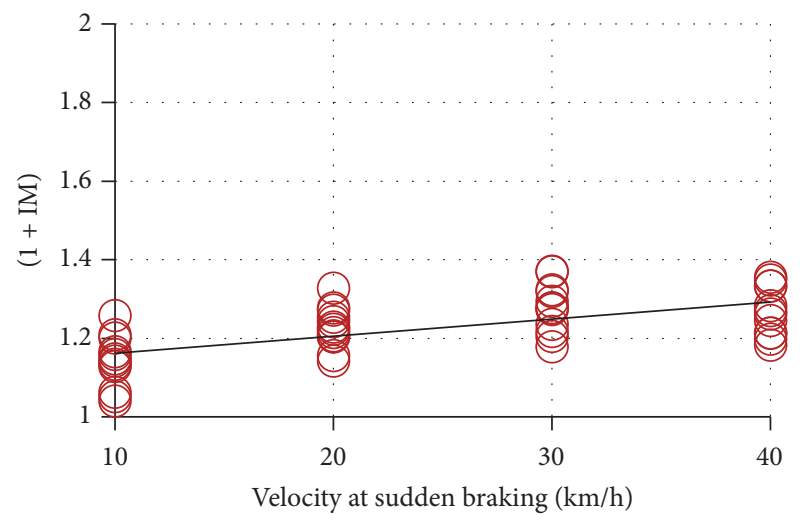

FIGURE 11: $(1+\mathrm{IM})$ versus velocity at sudden braking of $3 \mathrm{~L} / 8$ position.

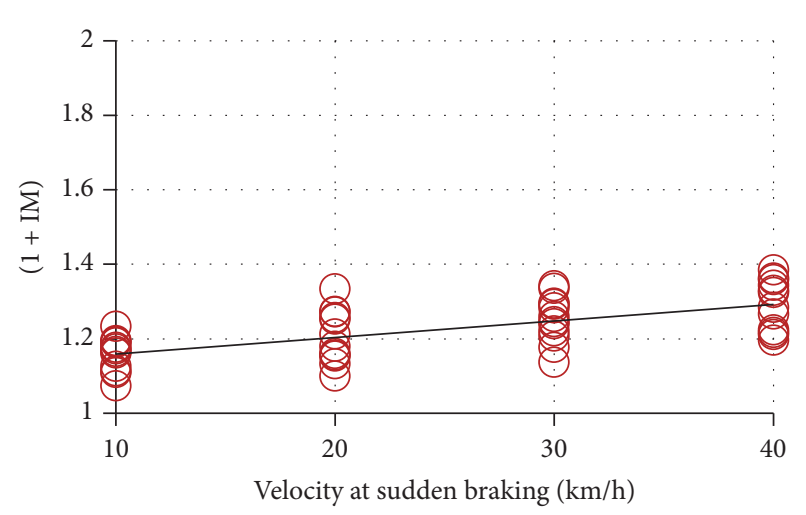

FIGURE 12: $(1+\mathrm{IM})$ versus velocity at sudden braking of $L / 2$ position.

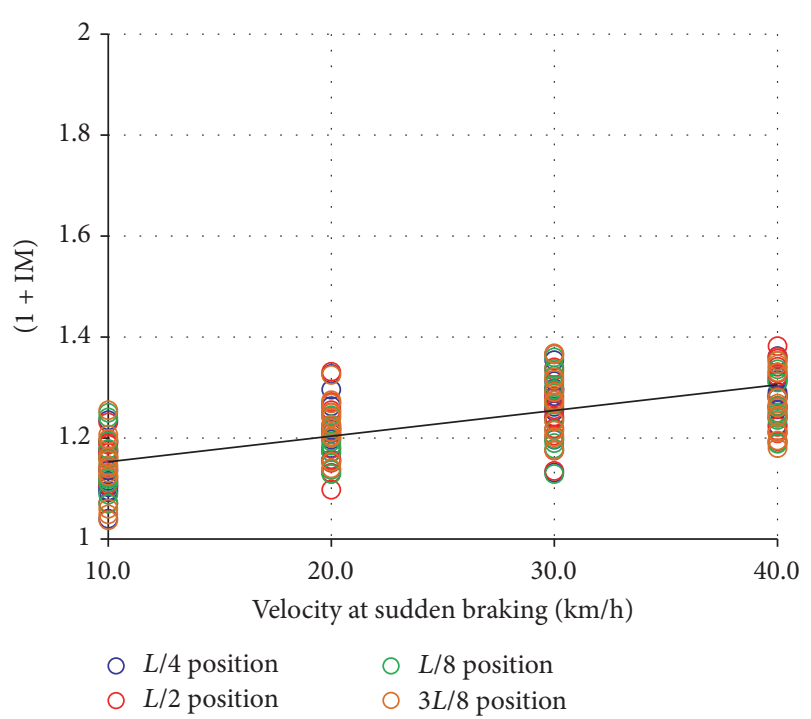

FIGURE 13: $(1+\mathrm{IM})$ versus velocity at sudden braking of all positions.

increasing the distance from the bearing location of first span. The variation of $(1+\mathrm{IM})$ with braking positions is shown from Figures 14-18. In this study, the magnitude of velocity varies from $10 \mathrm{~km} / \mathrm{h}$ to $40 \mathrm{~km} / \mathrm{h}$. Due to local traffic law, the speed of the truck cannot surpass $40 \mathrm{~km} / \mathrm{h}$. 


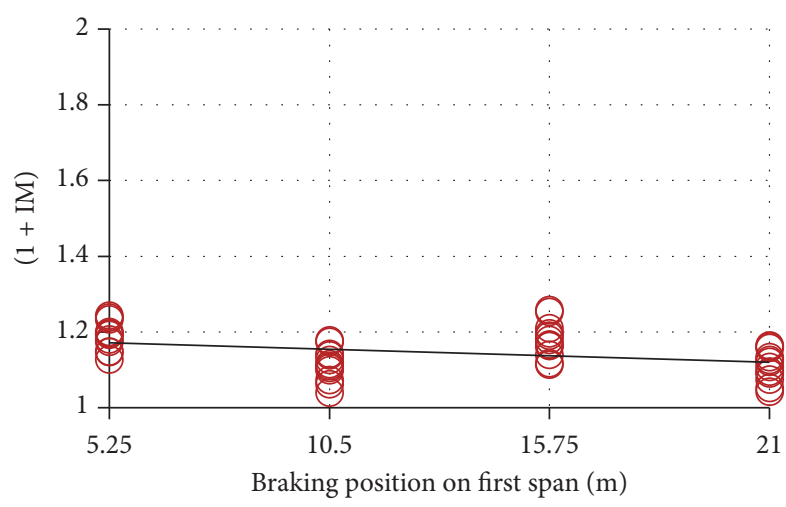

Figure 14: $(1+\mathrm{IM})$ versus braking position, $V=10 \mathrm{~km} / \mathrm{h}$.

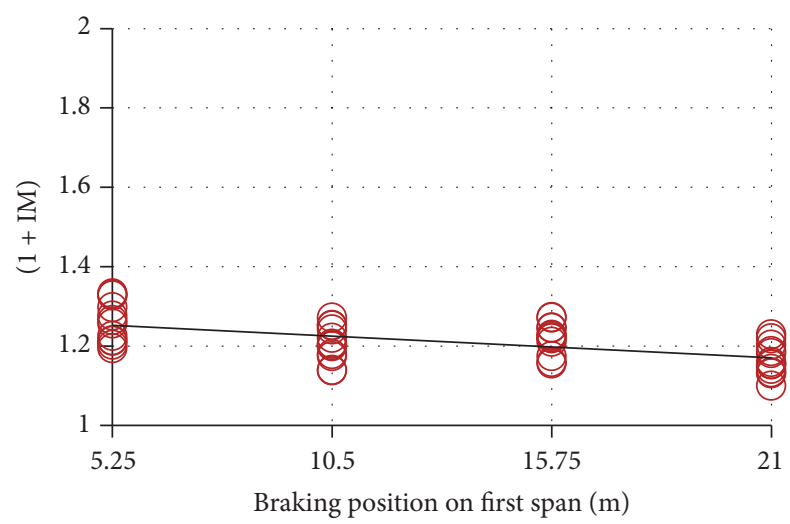

FIGURE 15: $(1+\mathrm{IM})$ versus braking position, $V=20 \mathrm{~km} / \mathrm{h}$.

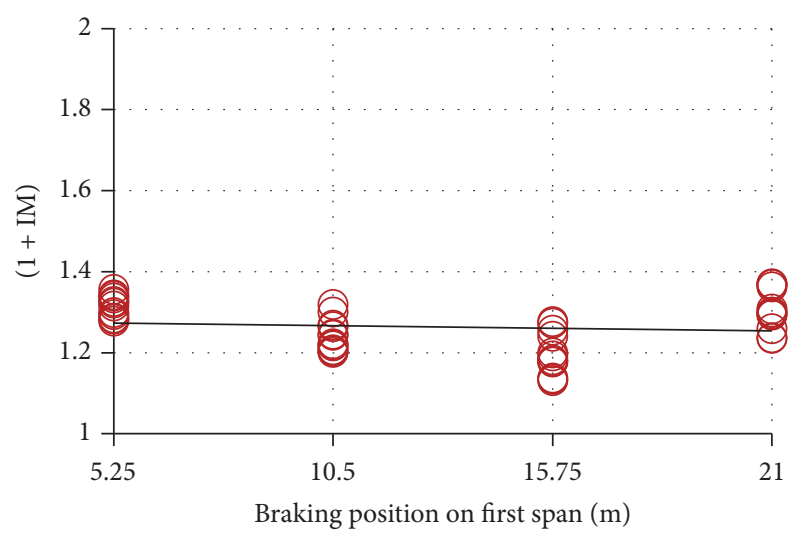

Figure 16: $(1+\mathrm{IM})$ versus braking position, $V=30 \mathrm{~km} / \mathrm{h}$.

\section{Conclusions}

This study introduces the results of research on dynamic interaction model between a three-axle vehicle and a continuous concrete girder bridge considering braking effects. The FEM has been applied to vibration analysis of the Hoa-Xuan bridge. The FEM results were verified by the experiments. The FEM results agree well with the experimental outcomes. The main contribution of this study is to validate the FEM results with the experimental results of continuous girder bridges.

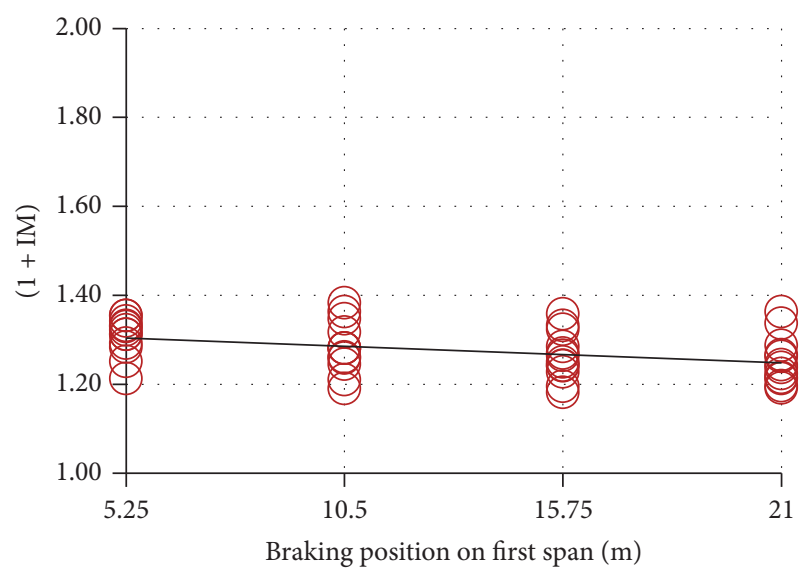

FIGURE 17: $(1+\mathrm{IM})$ versus braking position, $V=40 \mathrm{~km} / \mathrm{h}$.

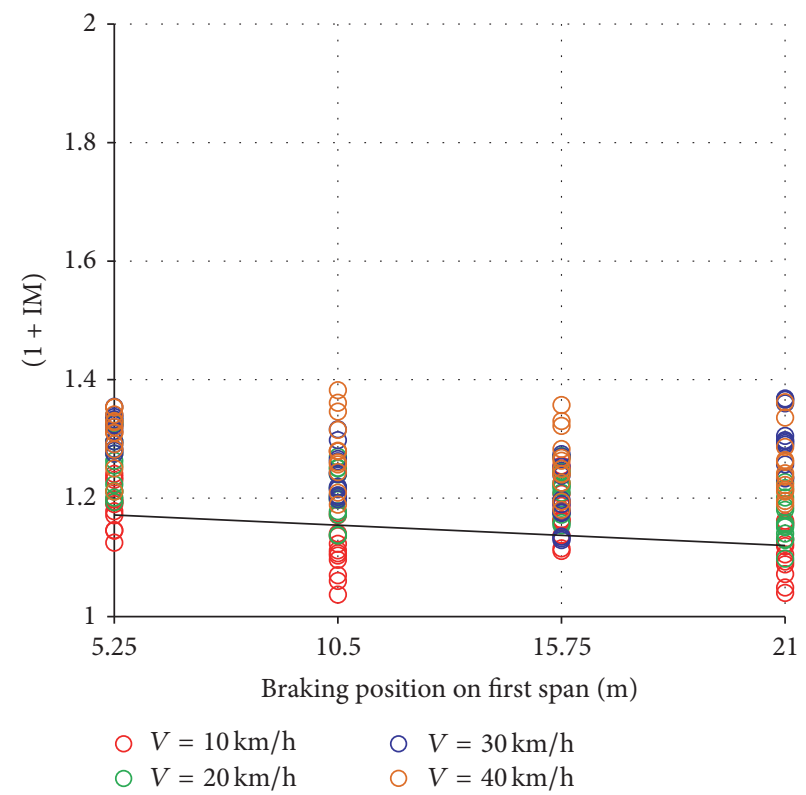

FIgURE 18: $(1+\mathrm{IM})$ versus braking position, $V=10 \div 40 \mathrm{~km} / \mathrm{h}$.

As observed from the experimental outcomes, the $(1+\mathrm{IM})$ increases with an increase in velocity at sudden braking and the $(1+$ IM) decreases with increasing the distance from the bearing location of span. Thus, the findings from this study can be practically used as additional references for current bridge codes by bridge engineers and researchers when dealing with related matters.

\section{Conflicts of Interest}

The authors declare that there are no conflicts of interest regarding the publication of this article.

\section{References}

[1] R. Willis, Appendix Report of the Commissioners Appointed to Inquire into the Application of Iron to Railway Structures, William Clowes, HM Stationary Office, London, UK, 1849. 
[2] H. H. Jeefcot, "On the vibration of girder under the action of moving loads," Philosophical Magazine, vol. 7, no. 48, pp. 66-97, 1929.

[3] S. Timoshenko and D. H. Young, Vibration Problems in Engineering, Van Nostrand Company, New York, NY, USA, 3rd edition, 1955.

[4] L. Fryba, "Quasi-static distribution of braking and starting forces in rails and bridge," Rail International, vol. 5, no. 11, pp. 698-716, 1974.

[5] H. Kishan and R. W. Trail-Nash, "A modal method for calculation of highway bridge response with vehicle braking," Civil Engineering Transactions, Institution of Engineers, Australia, vol. 19, no. 1, pp. 44-50, 1977.

[6] R. K. Gupta and R. W. Traill-Nash, "Bridge dynamic loading due to road surface irregularities and braking of vehicle," Earthquake Engineering \& Structural Dynamics, vol. 8, no. 2, pp. 83-96, 1980.

[7] N. L. Mulcahy, "Bridge response with tractor-trailer vehicle loading," Earthquake Engineering \& Structural Dynamics, vol. 11, no. 5, pp. 649-665, 1983.

[8] Y. B. Yang and Y. S. Wu, "A versatile element for analyzing vehicle-bridge interaction response," Engineering Structures, vol. 23 , no. 5, pp. 452-469, 2001.

[9] H. Hu and Q. Han, "Three dimensional modeling and dynamic analysis of four-wheel-steering vehicles," Acta Mechanica Sinica, vol. 19, no. 1, pp. 79-88, 2003.

[10] S. S. Law and X. Q. Zhu, "Bridge dynamic responses due to road surface roughness and braking of vehicle," Journal of Sound and Vibration, vol. 282, no. 3-5, pp. 805-830, 2005.

[11] S.-H. Ju and H.-T. Lin, "A finite element model of vehicle-bridge interaction considering braking and acceleration," Journal of Sound and Vibration, vol. 303, no. 1-2, pp. 46-57, 2007.

[12] A. González, C. Rowley, and E. J. OBrien, "A general solution to the identification of moving vehicle forces on a bridge," International Journal for Numerical Methods in Engineering, vol. 75, no. 3, pp. 335-354, 2008.

[13] Z. Zhao and N. Uddin, "Field calibrated simulation model to perform bridge safety analyses against emergency braking of trucks," Engineering Structures, vol. 56, pp. 2253-2262, 2013.

[14] L. Deng, W. He, and Y. Shao, "Dynamic impact factors for shear and bending moment of simply supported and continuous concrete girder bridges," Journal of Bridge Engineering, vol. 20, no. 11, 2015.

[15] O. C. Zienkiewicz and R. L. Taylor, The Finite Element Method, Butterworth-Heinemann, Oxford, UK, 5th edition, 2000.

[16] AASHTO, LRFD Bridge Design Specifications, AASHTO, Washington, DC, USA, 2012. 


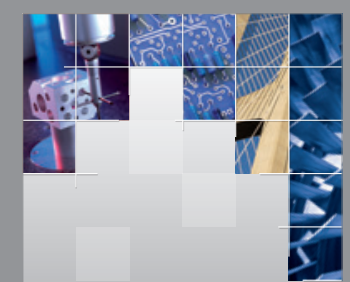

\section{Enfincering}
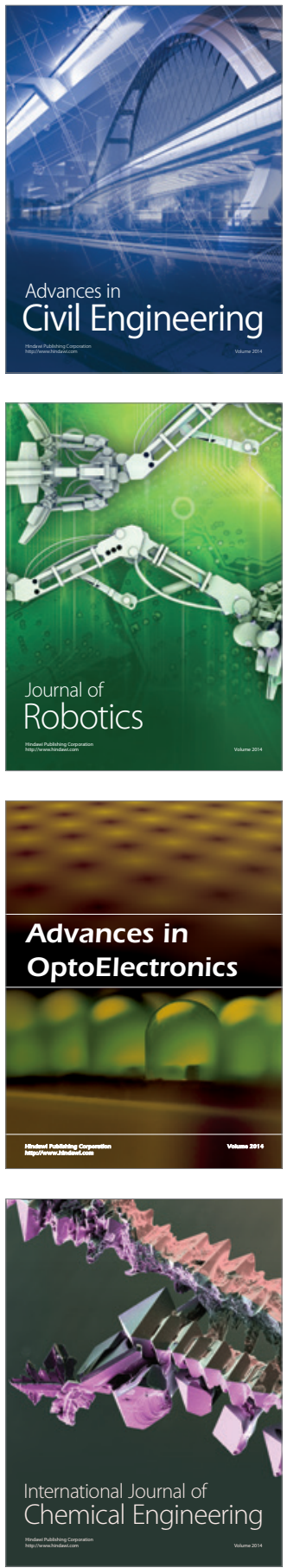

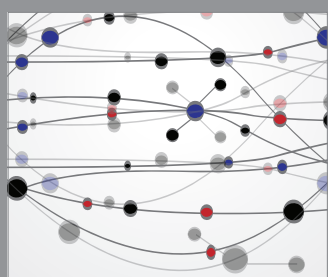

The Scientific World Journal

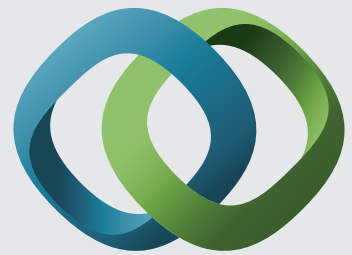

\section{Hindawi}

Submit your manuscripts at

https://www.hindawi.com
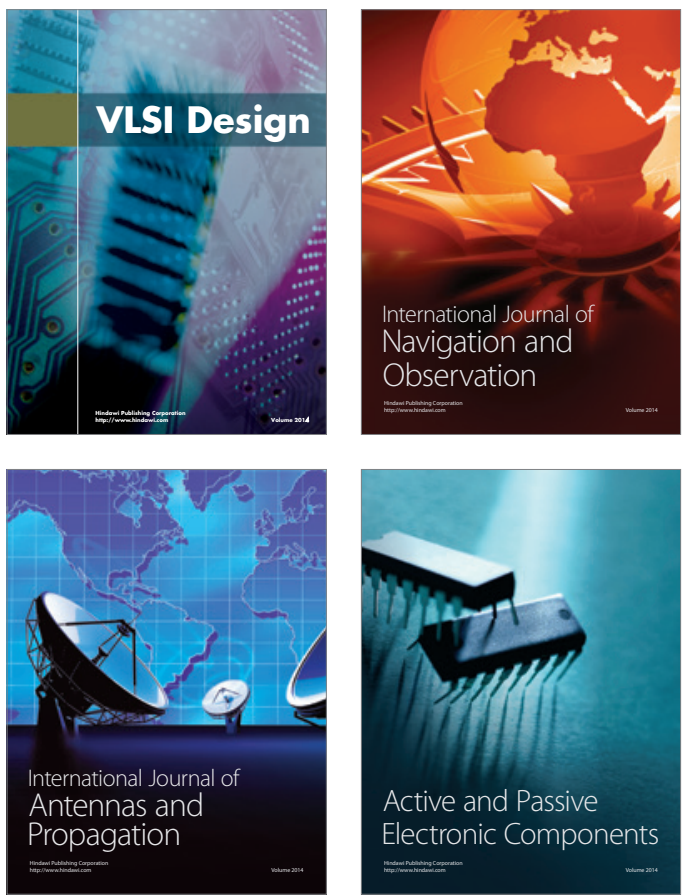
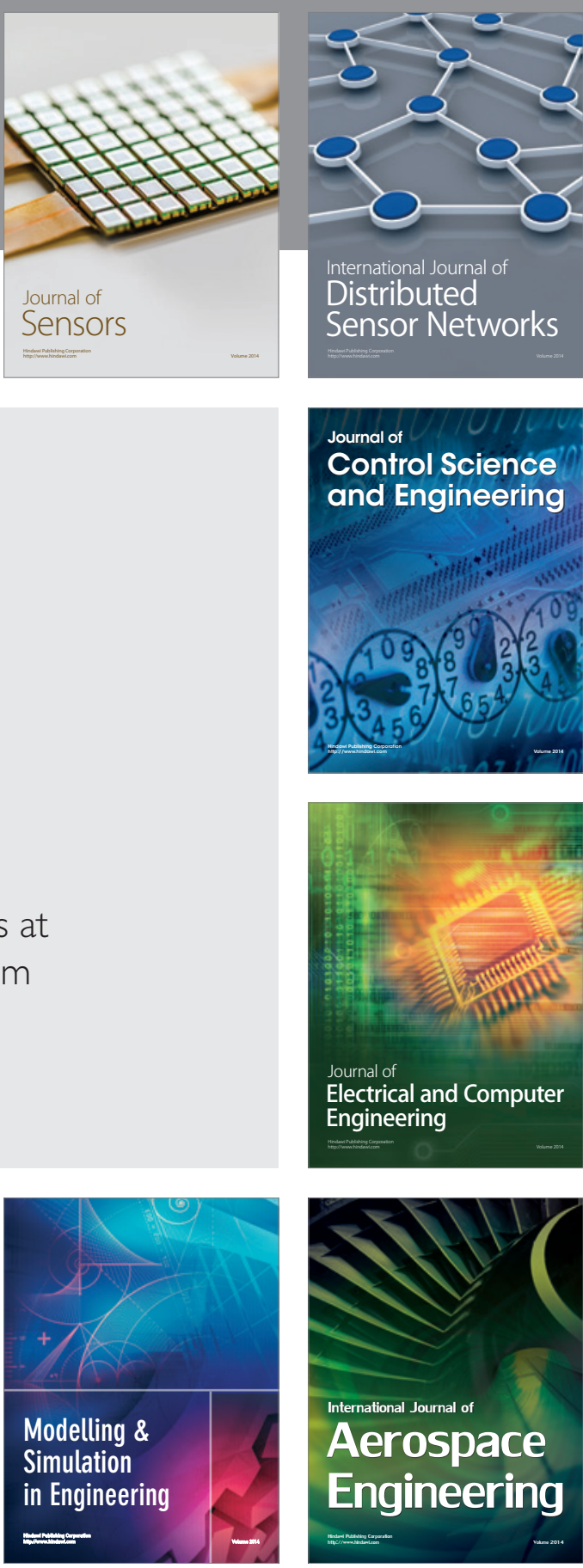

International Journal of

Distributed

Sensor Networks

$-$

Joumal of

Control Science

and Engineering
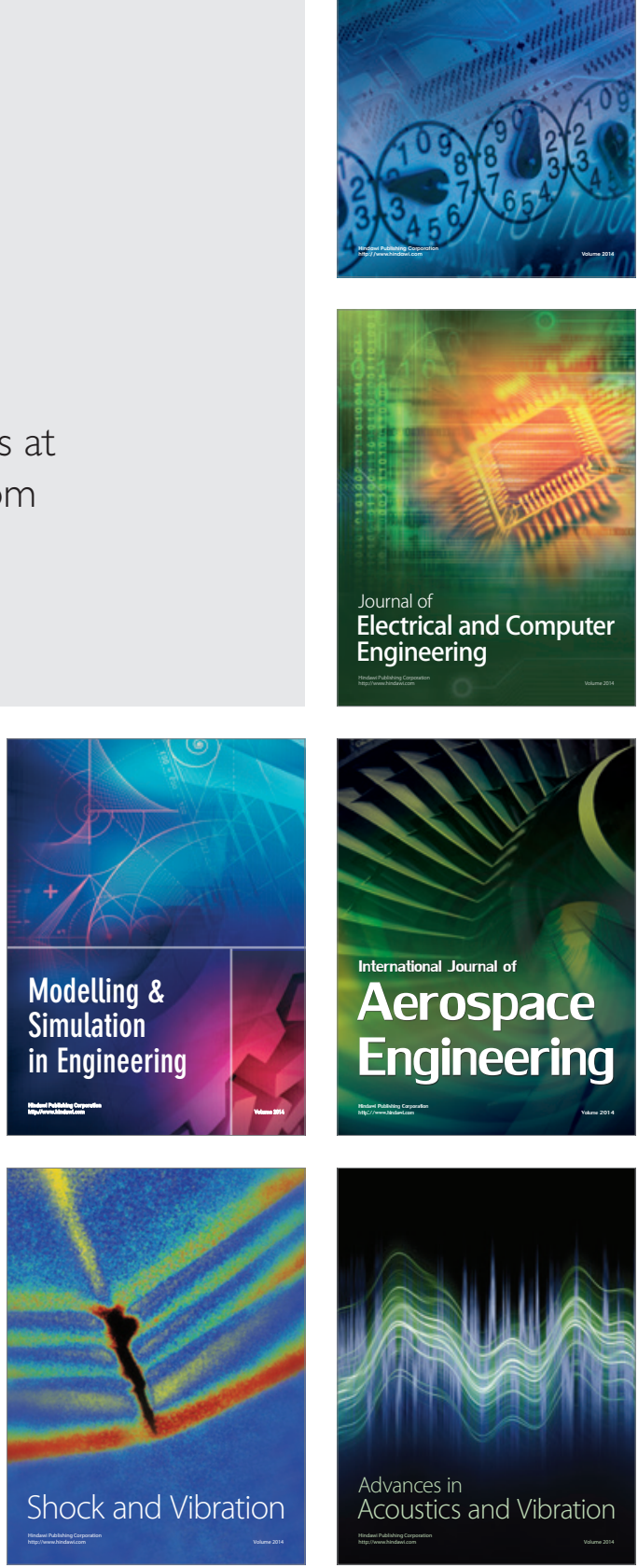